Abstract 365 Figure 2 Percentage of various histological grades on renal biopsy.

\begin{tabular}{|l|l|}
\hline Parameter & Result \\
\hline No of HSP & 314 \\
\hline No of HSPN & $64(20.4 \%)$ \\
\hline Hypertension & $24(37.5 \%)$ \\
\hline Deranges RFT at admission & $5(7.8 \%)$ \\
\hline Gross hematuria & $17(26.5 \%)$ \\
\hline Relapse & $13(20.3 \%)$ \\
\hline Kidney biopsy & $48(75 \%)$ \\
\hline Death & 1 \\
\hline CKD & 0 \\
\hline
\end{tabular}

Abstract 365 Figure 3 Treatment in patients with HSPN.

\begin{tabular}{|l|l|}
\hline Clinical subtype & Percentage \\
\hline Massive proteinuria & 56.7 \\
\hline Minimal proteinuria & 21.7 \\
\hline Moderate proteinuria & 15 \\
\hline Isolated hematuria & 6.7 \\
\hline
\end{tabular}

ultrasound reveals interventricular septum of $18 \mathrm{~mm}$ thickness, posterior wall of left ventricle of $15 \mathrm{~mm}$ thickness, with an intraventricular pressure gradient of $60 \mathrm{mmHg}$ at rest.

Conclusions Our patient has the severe, obstructive form of cardiomyopathy. This was the cause of the respiratory symptoms, despite the interstitial pulmonary disease. As a consequence, we changed diltiazem to verapamil, reduced the vasodilators and the corticosteroid doses, which lead to the net improvement of the symptoms. In systemic scleroderma, respiratory symptoms must not be taken "for granted" as being produced by interstitial lung disease., but must be evaluated correctly and completely at each consult.

\section{IMMUNE THROMBOCYTOPENIA ASSOCIATED WITH LOCALISEDLOCALIZED SCLERODERMA- REPORT OF 4 PAEDIATRICPEDIATRICCASES}

${ }^{1}$ A Jindal*, 'A Gupta, ${ }^{2} S$ Dogra, ${ }^{1}$ A Rawat, ${ }^{1} D$ Suri, ${ }^{3} J$ Ahluwalia, 'S Singh. ${ }^{1} P G I M E R$, Paediatrics, chandigarh, India; ${ }^{2} P G I M E R$, Dermatology, chandigarh, India; ${ }^{3} P G I M E R$, Haematology, chandigarh, India

\subsection{6/lupus-2017-000215.368}

Background and aims Many autoimmune and inflammatory diseases have been found to be associated with morphea. Thrombocytopenia, however, has rarely been reported

Aim-To describe the profile of 4 patients with localised scleroderma and thrombocytopenia
Methods A retrospective case record review of children diagnosed to have localised scleroderma in the paediatric rheumatology clinic of a tertiary care referral institute in North-West India. Children who also had thrombocytopenia (i.e. platelet counts $<150 \times 10^{3} / \mathrm{L}$ ) were analysed.

Results Twenty two children were diagnosed with localised scleroderma (10 boys and 12 girls, male: female ratio 1:1.2). Thrombocytopenia was identified in 4 children (prevalence$18 \%)$. The details of these 4 cases are summarised in Table 1. All 4 cases had en coup de sabre (ECDS) type of linear scleroderma. (Figure 1) Peripheral smear examination revealed normal platelet size. The lowest platelet counts ranged from $8 \times 10^{9} / \mathrm{L}$ to $120 \times 10^{9} / \mathrm{L}$. ANA was positive in 2 patients (case 1 and 2) and case 1 also had positive lupus anticoagulant in her serum. Methotrexate $(0.5 \mathrm{mg} / \mathrm{kg} /$ week $)$ was used for the treatment of morphea in 3 patients while one child was treated with topical calcipotriol ointment alone. No specific therapy was prescribed for thrombocytopenia, except in case 1 where thrombocytopenia was treated with injection anti D. Platelet counts recovered in 3 patients, while thrombocytopenia is still persisting in one patient.

Conclusions Thrombocytopenia associated with localised scleroderma in children is usually benign, has a probable autoimmune aetiology, requires no specific therapy and is generally curable with the systemic immunosuppressant medications used for the treatment of scleroderma 